\title{
FATTY ACID ETHYL ESTERS FROM MICROALGAE OF Scenedesmus ecornis BY ENZYMATIC AND ACID CATALYSIS
}

Gabryelle F. de Almeida ${ }^{\mathrm{a}}$, Pedro H. F. de Araújo ${ }^{\mathrm{b}}$, Alexandro C. Florentino ${ }^{\mathrm{b}}$, Roberto M. Bezerrab ${ }^{\mathrm{b}}$ José C. T. Carvalho Silvia M. M. Faustino a and Irlon M. Ferreira ${ }^{\mathrm{b}, *}$

aDepartamento de Ciências Biológicas e da Saúde, Colegiado de Farmácia, Universidade Federal do Amapá, Rod. JK, km 02, 68903-758 Macapá - AP, Brasil

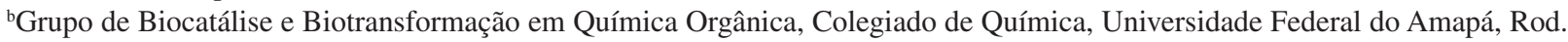
JK, km 02, 68902-280 Macapá - AP, Brasil

Recebido em 23/03/2017; aceito em 18/09/2017; publicado na web em 08/11/2017

\begin{abstract}
Microalgae are an indispensable food source for the various growth stages of mollusks, crustaceans, and several fish species. Using a microalgae biomass present in the Amazonian ecosystem (Macapá-AP), we study extraction methods for fatty acid such as solvent extraction (magnetic stirring and/or Soxhlet) and/or hydrolysis (acid and/or enzymatic catalysis) followed by esterification and/or direct transesterification. Extraction of crude triacylglycerides by mechanical stirring at room temperature was more efficient than continuous reflux (Soxhlet). Subsequently, the lipid extract was subject to transesterification with ethanol and CAL-B as a biocatalyst, leading to production of fatty acid ethyl esters (FAEE). Additionally, FAEEs were prepared by hydrolysis of crude triacylglycerides followed by acid-mediated esterification or enzymatic catalysis (lipase). In this case, the type of catalyst did not significantly influence FAEE yields. In the lipid extract, we identified palmitic, linoleic, oleic, and stearic acids with palmitic acid being the most abundant. Our results suggest that enzymatic catalysis is a viable method for the extraction of lipids in the microalga, Scenedesmus ecornis.
\end{abstract}

Keywords: algae; biocatalysis; source of lipids; Candida antarctica lipase.

\section{INTRODUCTION}

Scientists consider any organism with chlorophyll a and an undifferentiated stem in roots, stem and leaves as an algae (the first freshwater and marine freshwater photosynthetic organisms in the food chain). Cyanobacteria are also included in this definition, although they are prokaryotic organisms. ${ }^{1,2}$

It is estimated that there are more than 50,000 species of microalgae, however a little less than 30,000 thousand have already been studied and characterized. ${ }^{3}$ They are present mostly in marine environments, but also colonize sweet environments and have an enormous capacity to produce biomass per unit area and time, due to its rapid metabolism, allowing the duplication of the biomass in optimal conditions in a time of only 24 renewable energy.,5

Microalgae are an indispensable source of food for various growth stages of mollusks, crustaceans, and several fish species. ${ }^{6}$ In addition, studies on eukaryotic microalgae have found these to contain numerous bioactive compounds, including carotenoids, pigments, polysaccharides, polyphenols, and lipids ${ }^{6-8}$

Lipids extracted from microalgae biomass can be an invaluable source of biofuels. They include fatty acid ethyl esters (FAEE), bioethanol, biomethane, jet fuel, biohydrogen, and thermochemical conversion products such as bio-oil, biocrude, and syngas. ${ }^{9}$

Different catalysts have been reported in literature for the production of biodiesel from microalgae biomass, including metal oxides, ${ }^{10}$ enzymes, ${ }^{11,12}$ and homogeneous catalysts. ${ }^{13}$ Moreover, biodiesel production by enzymatic catalysis has several advantages, such as low energy consumption, mild reaction condition, low environmental impact, and high capacity of reuse. ${ }^{12,14}$

The extraction method and polarity of the solvent have been found to influence the lipid composition of microalgae, thereby interfering

*e-mail: irlon.ferreira@gmail.com with the quality of fuel. ${ }^{15,16}$ D'Oca and colleagues ${ }^{15}$ showed that a chloroform-methanol mixture $(2: 1 \mathrm{v} / \mathrm{v})$ was best for lipid extraction from a dry biomass of Chlorella pyrenoidosa, followed by methanol, chloroform, ethanol, and hexane.

The microalgae marine flora located in the state of Amapá, on the Brazilian Equatorial Cost, remains understudied. This paper aimed to investigate the fatty acid composition in the biomass of Scenedesmus ecornis by GC-MS and to evaluate the best method of extraction of these fatty acids, as well as to convert them to fatty acid ethyl esters (FAEE).

\section{EXPERIMENTAL}

\section{Materials}

Candida antarctica lipase immobilized on the acrylic resin (CALB; Novozyme 435 ${ }^{\circledR}, 5.000 \mathrm{U}$ ) was purchased from SigmaAldrich; chloroform (98.5\%) and ethanol (99\%) from Vetec; hexane (98.5\%) from Synth (Brazil). Sulfuric acid (98\%) and anhydrous sodium sulfate $(99.5 \%)$ were purchased from Synth. Salts for use in culture medium were obtained from Synth.

\section{Collection, isolation and identification of $S$. ecornis}

The microalgae were collected from the Indian Pond $\left(48^{\circ} 76^{\prime} 15^{\prime \prime} \mathrm{W} 0^{\circ} 37^{\prime} 79^{\prime \prime} \mathrm{N}\right)$ and the Curiaú Environmental Protection Area $\left(51^{\circ} 01^{\prime} 10^{\prime \prime} \mathrm{W} 00^{\circ} 12^{\prime} 58^{\prime \prime} \mathrm{N}\right)$ in the city of Macapá-AP using a phytoplankton net of $20 \mu \mathrm{m}$ by applying an horizontal push on the water surface several times until final collection of material. To obtain unialgae cultures the species were identified in optical microscope and isolated through single-cell isolation using capillary pipettes. ${ }^{17}$ The single-cell isolated was cultivated in BG11 medium. The cultures were identified and stored for further analysis. 


\section{Culture conditions of $S$. ecornis}

A wet biomass was decanted into bottle flasks $(450 \mathrm{~mL}$ for cell culture). Posteriorly, the residual biomass was transferred to Petri dishes and frozen $\left(4{ }^{\circ} \mathrm{C}\right)$. After total freezing, the samples were subjected to lyophilization using a benchtop freeze-drier (Enterprise I model in AISI 304 stainless steel) for $24 \mathrm{~h}$.

\section{Extraction of triglycerides by magnetic stirring at room temperature/transesterification}

In a beaker $(150 \mathrm{~mL})$ were individually added $1.0 \mathrm{~g}$ of dry biomass and $50 \mathrm{~mL}$ of hexane, chloroform or chloroform-hexane mixture (1:1) under magnetically stirring $(300 \mathrm{rpm})$ for $24 \mathrm{~h}$ at room temperature. Next, crude triglyceride was filtered through Buchner funnel to separate the wet biomass and washed with hexane $(3 \mathrm{~mL})$. The organic phase was dried with anhydrous sodium sulfate and filtered again; excess solvent was evaporated and the lipid extract was weighed and stored for further use. The transesterification reactions of the triglycerides from biomass $S$. ecornis extracted by magnetic stirring at room temperature was carried out in tubes $(3 \mathrm{~mL})$ which contained a mixture of triglycerides, ethanol $(500 \mu \mathrm{L})$ and CAL-B ( $10 \% \mathrm{w} / \mathrm{w}$ in relation to dry triglycerides). The reaction took place in an orbital shaker at $30{ }^{\circ} \mathrm{C}$ and $150 \mathrm{rpm}$ by $24 \mathrm{~h}$. The products were washed with distillate water $(3 \times 1 \mathrm{~mL})$, dried with $\mathrm{Na}_{2} \mathrm{SO}_{4}$ and the solvent was removed by evaporation under low pressure.

\section{Extraction of triglycerides by continuous reflux extraction (Soxhlet)}

Soxhlet extraction was performed with $1.0 \mathrm{~g}$ dry biomass of S. ecornis, $50 \mathrm{~mL}$ of a solvent (chloroform, hexane or chloroformhexane mixture) for $3 \mathrm{~h}$ in reflux, equivalent to four cycles. Subsequently, the extract was dried with anhydrous $\mathrm{Na}_{2} \mathrm{SO}_{4}$ and filtered; the excess solvent was rotated and the crude lipid extract was weighed and stored for further use. The transesterification reactions of the triglycerides from biomass $S$. ecornis extracted by Soxhlet was carried out in tubes $(3 \mathrm{~mL})$ which contained a mixture of triglycerides, ethanol $(500 \mu \mathrm{L})$ and CAL-B $(10 \% \mathrm{w} / \mathrm{w}$ in relation to dry triglycerides). The reaction took place in an orbital shaker at $30{ }^{\circ} \mathrm{C}$ and $150 \mathrm{rpm}$ by $24 \mathrm{~h}$. The products were washed with distillate water $(3 \times 1 \mathrm{~mL})$, dried with $\mathrm{Na}_{2} \mathrm{SO}_{4}$ and the solvent was removed by evaporation under low pressure.

\section{Reaction of hydrolysis/esterification by enzymatic catalysis}

Hydrolysis/esterification reaction was performed in an Erlenmeyer flask $(250 \mathrm{~mL})$ with $1.0 \mathrm{~g}$ of lyophilized biomass, $50 \mathrm{~mL}$ of distilled water and $100 \mathrm{mg}(10 \% \mathrm{w} / \mathrm{w})$ of CAL-B. The reaction remained in orbital stirring $\left(150 \mathrm{rpm}\right.$ at $\left.30^{\circ} \mathrm{C}\right)$ for $48 \mathrm{~h}$. After this period, $30 \mathrm{~mL}$ of hexane was added and the mixture was filtered through Buchner funnel to separate the wet biomass. The biocatalyst was separated from the biomass by filtrate and washed with hexane ( 3 $\mathrm{mL})$, oven-dried $\left(30^{\circ} \mathrm{C}\right.$ for $\left.24 \mathrm{~h}\right)$, and stored for reuse. The organic fraction was extracted with ethyl acetate $(3 \times 30 \mathrm{~mL})$, dried over anhydrous sodium sulfate and further filtered, after which the excess solvent was evaporated and the mixture of fatty acids was weighed and stored. The reaction was performed in triplicate.

Further, in a vial $(3 \mathrm{~mL})$, we added the mixture of fatty acids (161 $\mathrm{mg})$ with CAL-B $(10 \% \mathrm{w} / \mathrm{w})$ and $500 \mu \mathrm{L}$ of ethanol. The reaction was kept under constant stirring $\left(150 \mathrm{rpm}\right.$ at $\left.30^{\circ} \mathrm{C}\right)$ for $24 \mathrm{~h}$. Then, the reaction was filtered, extracted with hexane $(3 \times 2 \mathrm{~mL})$ and dried with anhydrous $\mathrm{Na}_{2} \mathrm{SO}_{4}$. Finally, excess solvent was evaporated. The product of esterification passed through a filter containing silica gel eluted with $2 \mathrm{~mL}$ of hexane. The excess solvent was evaporated and the yield of the reaction was determined. The reaction was performed in triplicate.

\section{Reuse of the biocatalyst (CALB) in hydrolysis/esterification reaction}

The recovered CAL-B was reused for two consecutive cycles in the esterification of fatty acids from the microalgae biomass of $S$. ecornis by following the same procedure described above.

\section{Reaction of hydrolysis/esterification by acid catalysis $\left(\mathrm{H}_{2} \mathrm{SO}_{4}\right)$}

Hydrolysis/esterification of the lipid fraction using an acidic catalyst was carried out according to the methodology proposed by D'Oca et al. ${ }^{15}$ with modification. In the hydrolysis reaction, $1.0 \mathrm{~g}$ of dry biomass of $S$. ecornis was added to $50 \mathrm{~mL}$ of distilled water in an Erlenmeyer flask $(250 \mathrm{~mL})$. Finally, $1 \mathrm{~mL}(20 \% \mathrm{w} / \mathrm{v})$ of sulfuric acid was slowly added to the medium. The reaction remained in orbital stirring $\left(150 \mathrm{rpm}\right.$ at $\left.30^{\circ} \mathrm{C}\right)$ for $3 \mathrm{~h}$. After this period, hexane $(30 \mathrm{~mL})$ was added and the mixture was filtered through a Buchner funnel to separate the wet biomass. The organic fraction was extracted with ethyl acetate $(3 \times 30 \mathrm{~mL})$, dried over anhydrous $\mathrm{Na}_{2} \mathrm{SO}_{4}$, and again filtered. After this, the excess of the solvent was evaporated and the mixture of fatty acids was was weighed and stored. The reaction was performed in triplicate.

Next, in a vial ( $3 \mathrm{~mL})$, we added the mixture of fatty acids $(161 \mathrm{mg})$ with $\mathrm{H}_{2} \mathrm{SO}_{4}(10 \%$ w/v) and $500 \mu \mathrm{L}$ of ethanol. The reaction was kept under constant stirring $\left(150 \mathrm{rpm}\right.$ at $\left.30^{\circ} \mathrm{C}\right)$ for $24 \mathrm{~h}$. Then, the reaction was filtered, extracted with hexane $(3 \times 2 \mathrm{~mL})$ and dried with anhydrous $\mathrm{Na}_{2} \mathrm{SO}_{4}$. Finally, excess solvent was evaporated. The product of esterification passed through a filter containing silica gel eluted with $2 \mathrm{~mL}$ of hexane. The excess solvent was evaporated and the yield of the reaction was determined. The reaction was performed in triplicate.

\section{Identification of fatty acids from S. ecornis by CG-MS}

Mass spectrometric analyses were performed using Shimadzu/ GC 2010 equipped with a fused silica column RTX-5 and coupled to an auto-injector (Shimadzu/AOC-5000) and a mass detector (Shimadzu MS2010 Plus) with electron impact $(70 \mathrm{eV})$. The analytical parameters were: split ratio, 1:20; carrier gas, helium; injection volume, $1.0 \mu \mathrm{L}$; injector temperature, $250{ }^{\circ} \mathrm{C}$; detector temperature, $250{ }^{\circ} \mathrm{C}$; column initial temperature, $50{ }^{\circ} \mathrm{C}$ for $1 \mathrm{~min}$; heating rate, 5 ${ }^{\circ} \mathrm{C} / \mathrm{min}$ to $250{ }^{\circ} \mathrm{C}$. The total analysis time was $45 \mathrm{~min}$. The fatty acid esters were identified by comparing the fragmentation spectra with those contained in the CG-MS library (MS database, NIST 5.0) and with literature data. ${ }^{4}$

\section{Statistical Analysis}

The results were evaluated by one-way analysis of variance, comparing the four treatments with a significant level of $p<0.5$.

\section{RESULTS AND DISCUSSION}

The $S$. ecornis, isolated from the Brazilian Equatorial Coast ecosystem, is a freshwater microalgae belonging to phylum Chlorophyta, class Chlorophyceae and family Scenedesmaceae, with significant variability in their lipid contents. ${ }^{18}$ The Chlorophyceae class includes numerous genera, but members of the Scenedesmus genus have a significant potential for oil production and the ability 
of rapid growth. In previous studies, Scenedesmus sp. showed the highest biomass and lipid content was compared to other oleaginous species as Botryococus and Chlorella. ${ }^{19,20}$

Several solvents have been described for the extraction of lipids from microalgae, such as chloroform, methanol, hexane, ethyl ether, or a combination of these. However, each medium favors the extraction of a particular lipid composition, since the lipids can be classified as polar or neutral lipids. ${ }^{20}$

In this study, the profile of fatty acids present in S. ecornis was investigated by means of a direct extraction of crude triglycerides at room temperature/mechanical stirring or in continuous reflux extraction (Soxhlet), followed by transesterification in the presence of a biocatalyst (Figure $1 \mathrm{~A}$ ) or using the lyophilized biomass followed by acid or enzymatic hydrolysis/esterification (Figure $1 \mathrm{~B}$ ).

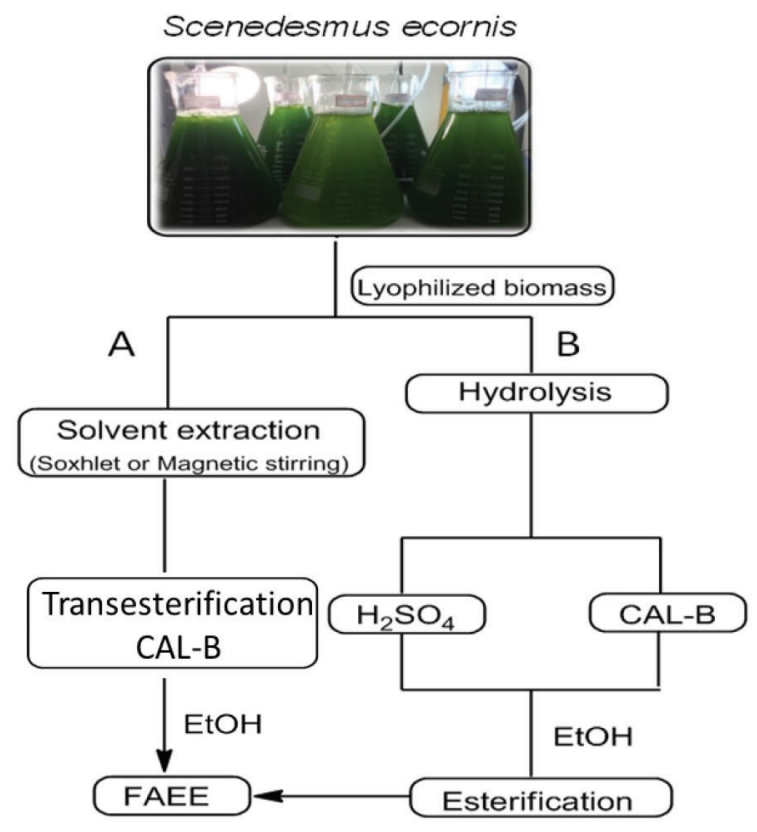

Figure 1. Production of FAEE from biomass present in S. ecornis

Significant differences were observed between different extraction methods (Magnetic stirring at room temperature and continuous reflux extraction - Soxhet) for all the solvents employed. Magnetic stirring at room temperature was able to extract a higher amount of total lipids present in S. ecornis (Figure 2). Each of the solvents exhibited different polarities: hexane (low polarity), chloroform (high polarity) and a mixture of both. For both agitation the room temperature method, the (chloroform-hexane 1:1) mixture was more effective in extracting the mixture of fatty acids. Using extraction method based on magnetic stirring at room temperature and chloroform-hexane $(1: 1)$ as a mixture of solvents, $40.60 \%( \pm 3.03)$ of lipids from biomass dry

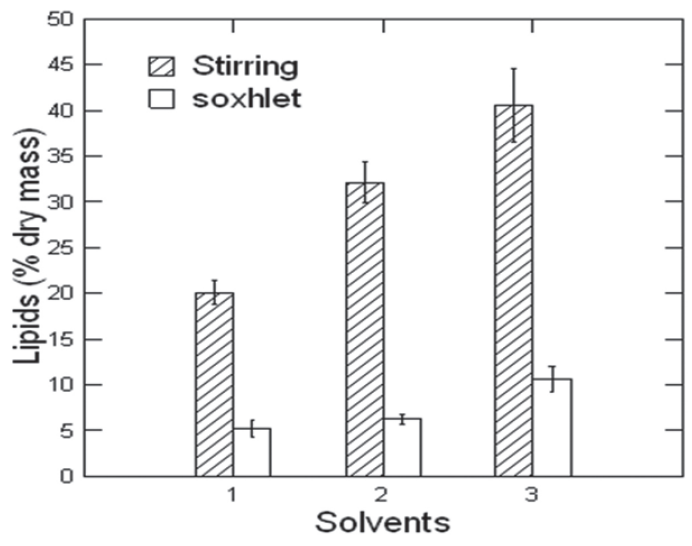

Figure 2. Total lipids extracted from S. ecornis microalgae using different solvents. 1. Chloroform; 2. Hexane; 3. Hexane:chloroform (1:1)

was obtained, compared to the efficiency of hexane $(32.16 \pm 1.68)$ and chloroform $20.13 \%( \pm 1.02)$ alone (Figure 2$)$.

For continuous reflux extraction (Soxhlet) method, the chloroform-hexane mixture was more effective in extracting the mixture of fatty acids $(10.6 \%, \pm 0.75)$, however a much less efficient yield when compared to stirring at room temperature method. Soxhlet extraction beyond extremely time-consuming, can cause thermal degradation of fatty acids. The inefficiency of Soxhlet extraction was also reported by other studies. ${ }^{21}$

The least efficient solvent for extraction was chloroform, indicating that most of the lipids present in the biomass of S. ecornis are best extracted by intermediate polarity in nature. Esakkimuthu et $a l .{ }^{22}$ reported the use of chloroform-methanol (2:1) mixture as being more efficient in extracting total lipids from Scenedesmus obliquus microalgae.

Saturated fatty acids identified by CG-MS analysis on lipid fractions were palmitic acid (C16:0) and stearic acid (C18:0); the unsaturated fatty acids found in higher amounts were oleic acid (C18:1) and linoleic acid (18:2) (Table 1). Based on the results, we could conclude that the presence of these fatty acids in S. ecornis offers a greater viability for the production of FAEEs from this microalga. Chng et al. ${ }^{23}$ identified palmitic acid as the major fatty acid in Scenedesmus dimorphus, obtained from the Algae Culture Collection at University of Texas. Palmitic acid (C16:0) was also the most significant fatty acid identified by Schulze et al. ${ }^{24}$ in Scenedesmus obtusiusculus, isolated from Lake Prerow in Germany.

In addition, for the hydrolysis-esterification process (method B), CAL-B was used as an enzymatic catalyst and $\mathrm{H}_{2} \mathrm{SO}_{4}$ as an acid catalyst. The results were summarized in Table 1 . In both catalytic processes, palmitic acid was the most abundant among the fatty acids identified (Table 1$)$. Palmitic acid $(\mathrm{C} 16: 0)$ relative conversion was found to be $54.4 \%$ by CAL-B and $72.2 \%$ by $\mathrm{H}_{2} \mathrm{SO}_{4}$, respectively. Furthermore the second most abundant acid in the

Table 1. Determination of FAEEs by GC-MS from S. ecornis biomass by enzymatic and acid catalysis.

\begin{tabular}{|c|c|c|c|c|}
\hline aFAEE (n:u) & Peaks ${ }^{\mathrm{b}}$ & Retetion time (min) & Conversion $(\%)($ CALB $)$ & Conversion $(\%)\left(\mathrm{H}_{2} \mathrm{SO}_{4}\right)$ \\
\hline Palmitic (16:0) & 1 & 16.9 & 54.40 & 72.22 \\
\hline Linoleic (18:2) & 2 & 19.5 & 4.57 & 12.69 \\
\hline Oleic (18:1) & 3 & 19.6 & 21.36 & 10.48 \\
\hline Stearic (18:0) & 4 & 20.0 & 19.67 & 4.61 \\
\hline$\sum$ Unsaturated & $* *$ & $* *$ & 25.93 & 23.17 \\
\hline$\sum$ Saturated & $* *$ & $* *$ & 74.07 & 76.83 \\
\hline
\end{tabular}

${ }^{\mathrm{a}}$ FAEE equivalent to the respective fatty acids and (n:u) number of carbons unsaturated. ${ }^{\mathrm{b}}$ See supporting information. 
hydrolysis-esterification process via enzymatic catalysis was oleic acid (18:1) with $21.36 \%$ relative conversion. The acid catalysis yielded linoleic acid (18:2), polyunsaturated with $12.69 \%$. Since linoleic acid is polyunsaturated, it may be suggested that the fitting of triglyceride chains containing linoleic acid derivatives is not favorable to the active site of CAL-B. In this sense, the method chosen in the hydrolysis-esterification process influences the composition of triglycerides from S. ecornis biomass (Table 1).

FAEE yield after hydrolysis-esterification reaction from reused CAL-B remained the same, in which the volume of lipid extract was $83 \%$ at first reuse and $78 \%$ at second reuse. This demonstrates that CAL-B is viable for reuse up to two consecutive cycles in the hydrolysis-esterification process, because there was no significant loss in its enzymatic activity.

The final yield of FAEE was significantly influenced by the methods applied, transesterification (Figure $1 \mathrm{~A}$ ) or hydrolysis/ esterification (Figure $1 \mathrm{~B}$ ). In the transesterification (A), the final yield of FAEE was influenced by extraction method (magnetic stirring at room temperature or Soxhlet) in chloroform-hexane. In the hydrolysis/esterification (B), the type of catalyst used (acid or enzymatic) did not significantly influence the FAEE yield. The FAEE yield was lower when lipid extraction was performed by Soxhlet (method A), obtaining only $2.43 \%( \pm 0.56)$. The yields by hydrolysis-esterification (method B) via acid catalysis and enzymatic catalysis were $17.23 \%( \pm 6.54)$ and $16.56 \%( \pm 6.81)$, respectively (Figure 3). However, although there were no significant differences in FAEE yields while using these catalysts, the hydrolysis-esterification process (method B) by CAL-B presented greater benefits, such as higher FAEE production, selectivity of unsaturated fatty acids (< polyunsaturated), reuse of catalyst without loss of yield of lipid extract, shortened FAEE purification step, and, consequently, reduction in cost of production.

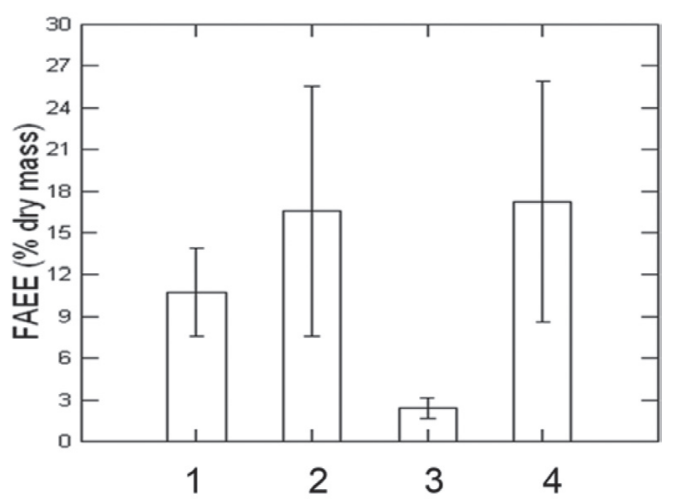

Figure 3. Production of FAEE by different methods. 1. Transesterification by stirring at room temperature (hexane-chloroform); 2. Hydrolysis/esterification by CAL-B; 3. Transesterification by Soxhlet (hexane-chloroform) and 4. Hydrolysis/esterification by $\mathrm{H}_{2} \mathrm{SO}_{4}$

\section{CONCLUSION}

We identified palmitic, linoleic, oleic and stearic acids as the main constituents in the lipid extract, with palmitic acid being the most abundant. The extraction yield was directly related to the polarity of the solvent. This study demonstrated that this microalgae is viable for the production of FAEEs to be used as a biodiesel or derivatives. The hydrolysis-esterification method by enzymatic catalysis is suggested to be a viable method for the extraction of lipids from S. ecornis and production of FAEEs.

\section{SUPPLEMENTARY MATERIAL}

Supplementary data related to this article can be found at http:// quimicanova.sbq.org.br

\section{ACKNOWLEDGMENTS}

G. F. A. thank Coordination of Improvement of Higher Level Personnel for scholarship. The authors would like to acknowledge, National Council for Scientific and Technological Development, and Federal University of Amapá for financial support (No 23125003351201556/PAPESQ).

\section{REFERENCES}

1. Lee, Y.; Chang, S.; Bioresource Technol. 2011, 102, 5297.

2. Galadima, A.; Muraza, O.; Energy 2014, 78, 72.

3. Kligerman, D. C.; Bouwer, E. J.; Renewable Energy 2015, 52, 1834.

4. Nautiyal, P.; Subramanian, K. A.; Dastidar, M. G.; Fuel. Process. Technol. 2014, 120, 79.

5. Bertin, M. J.; Zimba, P. V.; Beauchesne, K. R.; Huncik, K. M.; Moeller, P. D. R.; Harmful Algae 2012, 20, 111.

6. Adarme-Vega, T. C.; Lim, D. K. Y.; Timmins, M.; Vernen, F.; Li, Y.; Schenk, P. M.; Microb. Cell Fact. 2012, 11, 96.

7. Tinoco, N. A. B.; Uekane, T. M.; Tsukui, A.; Aguiar, P. F. D.; Teixeira, C. M. L. L.; Rezende, C. M.; J. Braz. Chem. Soc.2016, 27, 1452.

8. Soares, A. T.; Marques Júnior, J. G.; Lopes, R. G.; Derner, R. B.; Antoniosi Filho, N. R.; J. Braz. Chem. Soc. 2016, 27, 1083.

9. Ejike, C. E. C. C.; Collins, S. A.; Balasuriya, N.; Swanson, A. K.; Mason, B.; Udenigwe, C. C.; Trends Food Sci. Technol. 2017, 59, 30.

10. Suarez, P.; Pinto, A. C.; J. Braz. Chem. Soc. 2011, 22, 2023.

11. Khan, A. M.; Fatima, N.; Chin. J. Chem. Eng. 2016, 24, 388.

12. Liu, C-H.; Huang, C-C.; Wang, Y-W.; Lee, D-J.; Chang, J-S.; Appl. Energy 2012, 100, 41.

13. Galadima, A.; Muraza, O.; Energy 2014, 78, 72.

14. Ferreira, I. M.; Ganzeli, L.; Rosset, I. G.; Yoshioka, S. A.; Porto, A. L. M.; Catal. Lett. 2016, 147, 269.

15. D’Oca, M. G. M.; Viêgas, C. V.; Lemões, J. S.; Miyasaki, E. K.; MorónVillarreyes, J. A.; Primel, E. G.; Abreu, P. C.; Biomass Bioenergy 2011, $35,1533$.

16. Dianursanti, R. P.; Wijanarko, A.; Procedia Environ Sci. 2015, $23,412$.

17. Barsanti, L.; Gualtieri, P.; Algae: Anatomy, Biochemistry and Biotechnology, CRC, Taylor \& Francis: Boca Raton, 2006, pp. 209-250.

18. Sharma, T.; Gour, R. S.; Kant, A.; Chauhan, R. S.; Algal. Res. 2015, 12, 341.

19. Girisha, S. T.; Krishnappa, R.; Venkatachalapathy, G.; Mrunalini, B. R.; Arch. Appl. Sci. Res. 2014, 6, 131.

20. Ranjith, K. R.; Hanumantha, R. P.; Arumugam, M.; Frontiers in Energy Research 2015, 2, 61.

21. Esakkimuthu, S.; Krishnamurthy, V.; Govindarajan, R.; Swaminathan, K.; Biomass Bioenergy 2016, 88, 126.

22. Guldhe, A.; Singh, P.; Ansari, F. A.; Singh, B.; Bux, F.; Fuel 2017, 187, 180 .

23. Chng, L. M.; Chan, D. J. C.; Lee, K. T.; J. Clean Prod. 2016, 130, 68.

24. Schulze, C.; Reinhardt, J.; Wurster, M.; Ortiz-Tena, J. G.; Sieber, V.; Mundt, S.; Bioresour. Technol. 2016, 218, 498. 